\title{
Benign childhood epilepsy with centro-temporal spikes
}

\author{
Evolutive clinical, cognitive and EEG aspects
}

\author{
Glória M.A.S. Tedrus', Lineu C. Fonseca', Dioraci P. Castilho', \\ Elizabeth M.C. Pacheco ${ }^{2}$, Amanda A. Campregher ${ }^{3}$, Marina C. Bittar ${ }^{4}$
}

\begin{abstract}
Thirty-two children with benign childhood epilepsy with centrotemporal spikes (BECTS) were studied for a mean period of 27.6 months. The characteristics of the seizures, electroencephalogram (EEG), WISC-III and School Performance Test were compared at the start and end of the study. Nine (28.1\%) children continued having seizures. Epileptiform activity (EA) on the EEG reduced in number and was no longer recorded in 6 (18.7\%) children. There was a significant improvement in the performance and perceptual organization $1 \mathrm{Q}$ values. The improvement in reading performance failed to reach statistical significance. The performance in arithmetic worsened in $43.7 \%$ of the children, and this was associated with the persistence of epileptic seizures. There were no significant correlations between changes in cognitive aspects and characteristics of EA. There is a need to continue this study, and also search for other factors influencing the evolution of cognitive abilities in children with BECTS.
\end{abstract}

Key words: benign childhood epilepsy with centrotemporal spikes, rolandic epilepsy, epileptiform activity, cognition, rolandic spikes.

\section{Epilepsia benigna da infância com pontas centrotemporais: aspectos evolutivos clínicos, cognitivos e do EEG}

\section{RESUMO}

Foram estudados aspectos evolutivos clínicos, cognitivos e eletrencefalográficos (EEG) de 32 crianças com epilepsia benigna da infância com pontas centrotemporais (EBICT) acompanhadas por 27,6 meses. Foram comparadas as características das crises, do EEG, do WISC-III e do Teste de Desempenho Escolar ao início e ao final do estudo. Nove (28,1\%) crianças continuaram apresentando crises. A atividade epileptiforme (AE) ao EEG reduziuse em número e não mais foi registrada em $6(18,7 \%)$ crianças. Houve melhora significativa nos $\mathrm{Ql}$ de execução e de organização perceptual. A melhora do desempenho em leitura não alcançou significância estatística, enquanto em $43,7 \%$ das crianças houve piora em aritmética. Esta foi associada à persistência de crises epilépticas. Não houve correlações significativas entre aspectos cognitivos e características da AE. Há necessidade de estudar até a remissão total das crises e da $A E$, assim como procurar outros fatores que influenciem a evolução das habilidades cognitivas das crianças com EBICT.

Palavras-chave: epilepsia benigna da infância, eletrencefalograma, atividade epileptiforme, cognição.

\section{Correspondence \\ Gloria M.A.S. Tedrus \\ Rua Juçara 134 \\ 13094-552 Campinas SP - Brasil \\ E-mail: gmtedrus@uol.com.br}

Received 1 June 2009

Received in final form 22 December 2009

Accepted 30 December 2009
Benign childhood epilepsy with centro-temporal spikes (BECTS) is a focal idiopathic epilepsy of childhood that corre- sponds to an incidence of approximately one quarter of the cases of epilepsy in school age children. The neuropsychomo-

${ }^{1}$ Professor of Neurology, Pontifícia Universidade Católica de Campinas (PUC-Campinas), Campinas SP, Brazil; ${ }^{2}$ Professor of Psychology, PUC-Campinas; ${ }^{3}$ Placement Scholarship Student PIBIC/CNPq. School of Psychology, PUC-Campinas; ${ }^{3}$ Placement Scholarship Student FAPIC/Reitoria. School of Psychology, PUC-Campinas. 
tor development is normal, there being no evidence of cerebral injury, and the prognosis is good, since the seizures usually disappear by the age of 15 , with normalization of the EEG ${ }^{1}$.

However in recent decades, alterations in specific neuropsychological tests, learning difficulties and worsening of school performance have been referred to in a considerable proportion of these children. The deficits are mostly related to language, memory and execution functions ${ }^{2-8}$.

There is still controversy in the literature about the mechanisms involved in the cognitive deficits of this epileptic syndrome and longitudinal studies could provide contributions to knowledge of the relationships between the clinical and electro-encephalographic aspects, and also verify if the children show discreet deficits, stagnation or cognitive regression.

The longitudinal studies have been diversified with respect to the evaluation methods, populations studied, typical or atypical, and the time accompanied. Some studies have suggested that in BECTS, the cognitive deficit and school difficulties are transitory, as also the seizures and EEG alterations ${ }^{9-11}$, although discreet neuropsychological alterations ${ }^{11,12}$ and school difficulties could persist in the final evaluation according to parents and teachers ${ }^{10}$.

Thus the objective of this research was to study children with typical BECTS with respect to the relationships between the clinical, cognitive and electroencephalographic aspects, and also the basic elements of the school performance evaluation.

\section{METHOD}

\section{Participants}

Forty-nine children with BECTS from the Child Neurological Outpatients Department and Electroencephalographic Service of the Celso Pierro Hospital and Maternity Hospital of PUC-Campinas took part in the initial evaluation. For inclusion, the children attended the following criteria:

[1] Diagnosis of BECTS according to the International Classification of Epilepsies and Epileptic Syndromes ${ }^{13}$ and the Dalla Bernardina et al. criteria ${ }^{14}$;

[2] Normal neuropsychomotor development, neurological examination and neuroimage studies;

[3] Absence of a history of neurological and neurological problems;

[4] Consent of the parents to take part in the research and signing of a free and informed consent form as approved by the Ethics Committee for research with human beings.

Of the 49 children, consent was not given for 6 children to take part in the evolutive study and another 11 did not return for the evaluations.

Thirty-two children took part in the present evolu- tive study for a minimum period of accompaniment of one year and mean participation of 27.6 months (median: 23 months). Of these children, twenty were evaluated at two points in time, 8 on 3 occasions and 4 on 4 occasions. The ages varied from 7 to 11 years old and 17 were of the female gender.

\section{Procedures}

The following procedures were carried out:

[1] Medical history with the parents or person responsible and raising of the case histories containing the clinical and laboratory data. Of the clinical data with respect to the seizures, the age when they started, the number and type of seizure and the time since the last seizure were evaluated, and also the use of anti-epileptic medication.

[2] Conventional neurological examination.

[3] The School Performance Test (SPT) $)^{15}$ is a psychometric instrument validated and standardized for use in Brazil, with a favorable report by the Psychological Test Evaluation System (Federal Psychology Council, Brazil), which aims to offer, in an objective way, an evaluation of the fundamental capacities for school performance.

The SPT was conceived to evaluate children in the $1^{\text {st }}$ to $6^{\text {th }}$ grades, and indicates, in a wide reaching way, which school learning areas have been preserved or prejudiced in the child under examination ${ }^{15}$.

The SPT is made up of 3 sub-tests: [A] Writing - writing of words dictated to the individual; [B] Arithmetic oral solutions to problems and written calculations of arithmetical operations; [C] Reading - word recognition.

Each sub-test presents a scale of items in increasing order of difficulty, which are presented to the child independent of his school grade. The sub-test is stopped when the child is no longer able to solve the proposed situation. The net scores are calculated for each sub-test and hence the total net score can be calculated, which is converted into a classification per school grade using a table, the categories being upper, middle and lower, corresponding, respectively, to the $25 \%$ of subjects with the highest scores, the 25 to $75 \%$ in the middle group and the $25 \%$ with the lowest scores. It is possible to compare the net score with the expected score according to age.

[4] Edinburgh Inventory: instrument used to evaluate the lateral dominance of a child.

[5] Wechsler intelligence Scale for Children (WISCIII): used to determine cognitive performance in both qualitative and quantitative terms. This scale proposes problems that allow for appreciation of the capacity of the subjects with respect to memory, attention, action planning, spatial orientation and other aspects connected to mental function. It is composed of 2 types of evaluation: that of cognitive performance related to verbal aspects (Verbal IQ) and that of cognitive performance relat- 
ed to non-verbal aspects, that is, of performance (Performance IQ).The following factorial indexes were also studied: verbal understanding, resistance to distraction, perceptual organization and processing velocity.

[6] Digital electroencephalogram: cerebral electrical activity was recorded with a resolution of 12 bits, 0.5 and $35 \mathrm{~Hz}$ filters, at a rate of 200 samples per second using the Braintech 3.0 equipment (EMSA Equipamentos Médicos). Impedance was maintained below $10 \mathrm{k} \Omega$. The electrodes were placed according to the 10-20 international system ${ }^{16}$ and the reference consisted of inter-connected auricular electrodes. The recording was made while resting, hyperventilation and, when possible, during spontaneous sleep.

The background activity and the presence of epileptiform activity (EA) were studied on the resting EEG. Localization, hemispheric laterality and the number of EA were examined. The EA were counted for a 5 minute sequence, the child remaining with his eyes shut, and the mean EA per minute then calculated. The EA was evaluated as being unilateral or bilateral and the laterality characterized considering its unilateral occurrence or its clear predominance in one of the cerebral hemispheres.

\section{Data analysis}

The relationships between the clinical and electroencephalographic aspects and the results of the SPT and WISC-III in the initial evaluation were studied, and the same aspects compared between the initial and final evaluations.

Parametric (t test, ANOVA) and non-parametric (Chi-square, Wilcoxon, Mann-Whitney test) statistical tests were used depending on the situation under analysis. The level of significance was $\mathrm{p}<0.05$.

With respect to the SPT, changes occurring in the superior, middle and inferior categories during the evolution were evaluated.

In order to identify possible differences between the group that took part in the evolutive study (32 children) and the group that only took part in the initial evaluation (17 children), these two groups were compared with respect to the following: age of the child, age at the first seizure, total number and type of seizures, time since the last seizure, total number of EA on the EEG and the results of the SPT and of the verbal, execution and total IQ values. No significant differences were detected between the groups (Mann-Whitney test, $\mathrm{p}>0.05$ ).

\section{RESULTS}

\section{Clinical and electroencephalographic aspects}

Table 1 shows the ages of the children at the start and end of the study, age when the first seizure occurred, time since the last seizure and approximate total number of epileptic seizures.

Nine (28.12\%) of the children had seizures during the period under observation.

At the time of the initial evaluation, fifteen children were taking anti-epileptic drugs (carbamazepine, phenobarbital or valproic acid) and 14 during the subsequent period.

All the children presented normal background activity on the resting EEG. Table 1 shows the locality, laterality and mean number of EA on the initial and final EEG.

The EA on the EEG reduced in number significantly (Wilcoxon, $\mathrm{p}=0.001$ ) during the study, and were no longer recorded on the final EEG in 6 (18.7\%) of the children.

\section{Cognitive aspects}

Table 2 shows the mean values and standard deviations for the IQ values and factorial indices in the initial and final evaluations, and the $\mathrm{p}$ values when compared (Wilcoxon for paired samples).

A statistically significant improvement in the performance and perceptual organization IQ values was observed (Wilcoxon, $\mathrm{p}<0.05$ ).

Table 1. Clinical and electroencephalographic characteristics in the initial and final evaluations of 32 children with BECTS.

\begin{tabular}{|c|c|c|}
\hline Clinical-electroencephalographic aspects & Initial & Final \\
\hline Age & $9.38 \pm 1.24$ & $11.69 \pm 1.57$ \\
\hline Age at $1^{\text {st }}$ seizure (years) & $6.25 \pm 1.87$ & - \\
\hline Time since last seizure (months) ${ }^{*}$ & $18.21 \pm 20.95$ & $40.69 \pm 30.44$ \\
\hline Total no. of epileptic seizures ${ }^{2}$ & $3.35 \pm 1.83$ & $4.27 \pm 2.55$ \\
\hline Mean $\mathrm{n} \%$ min. of $E A$ on the $E G^{3}$ & $9.42 \pm 13.47$ & $4.72 \pm 7.34$ \\
\hline \multicolumn{3}{|l|}{ Laterality of the $\mathrm{EA}^{* *}$} \\
\hline Right & 10 & 5 \\
\hline Left & 7 & 12 \\
\hline Bilateral & 13 & 9 \\
\hline Median & 2 & - \\
\hline
\end{tabular}

BECTS: benign childhood epilepsy with centro-temporal spikes; EA: epileptiform activity; *Wilcoxon Signed Ranks test, $p<0.05$; ${ }^{* *}$ Chi-square, not significant for bilateral EA versus unilateral. 
Table 2. Initial and final IQ values: means and standard deviations and p values (Wilcoxon for paired samples) in the comparisons.

\begin{tabular}{|c|c|c|c|c|c|}
\hline \multirow[b]{2}{*}{ IQ } & \multicolumn{2}{|c|}{ Initial } & \multicolumn{2}{|c|}{ Final } & \multirow[b]{2}{*}{$P$ value } \\
\hline & mean & SD & mean & SD & \\
\hline Verbal & 104.47 & 19.46 & 103.16 & 18.12 & 0.524 \\
\hline Performance & 101.59 & 17.93 & 107.59 & 14.83 & $0.025^{*}$ \\
\hline Total & 103.22 & 18.44 & 105.81 & 16.41 & 0.387 \\
\hline Verbal comprehension & 104.19 & 18.52 & 102.53 & 17.81 & 0.531 \\
\hline Perceptual organization & 100.84 & 19.69 & 108.18 & 15.69 & $0.013^{*}$ \\
\hline Resistance to distraction & 100.72 & 17.04 & 96.81 & 11.86 & 0.133 \\
\hline Processing velocity & 97.34 & 10.89 & 96.16 & 15.40 & 0.654 \\
\hline
\end{tabular}

*Wilcoxon signed ranks test, $\mathrm{p}<0.05$; SD: standard deviation.

Table 3. Distribution of the 32 children with BECTS according to their performance in the SPT in the initial and final evaluations and the $p$ values.

\begin{tabular}{|c|c|c|c|c|}
\hline \multirow[b]{2}{*}{ SPT } & \multicolumn{3}{|c|}{ Classification per school grade } & \multirow{2}{*}{$\begin{array}{c}\text { Chi-square } \\
\text { p value }\end{array}$} \\
\hline & & Initial & Final & \\
\hline Reading & $\begin{array}{l}\text { Superior/middle } \\
\text { inferior }\end{array}$ & $\begin{array}{l}11 \\
21\end{array}$ & $\begin{array}{l}17 \\
15\end{array}$ & 0.131 \\
\hline Writing & $\begin{array}{l}\text { Superior/middle } \\
\text { inferior }\end{array}$ & $\begin{array}{l}13 \\
19\end{array}$ & $\begin{array}{l}16 \\
16\end{array}$ & 0.451 \\
\hline Arithmetic & $\begin{array}{l}\text { Superior/middle } \\
\text { inferior }\end{array}$ & $\begin{array}{l}19 \\
13\end{array}$ & $\begin{array}{l}10 \\
22\end{array}$ & $0.024^{*}$ \\
\hline Total* & $\begin{array}{l}\text { Superior/middle } \\
\text { inferior }\end{array}$ & $\begin{array}{l}14 \\
18\end{array}$ & $\begin{array}{l}13 \\
19\end{array}$ & 0.800 \\
\hline
\end{tabular}

${ }^{*}$ Chi-square test, $\mathrm{p}<0.05$; SPT: school performance test; BECTS: benign childhood epilepsy with centro-temporal spikes.

Table 4. Correlation between the occurrence of epileptic seizures during the accompaniment and evolutive performance in the SPT sub-test for arithmetic.

\begin{tabular}{lcc} 
& With epileptic seizures & Without epileptic seizures \\
\hline Arithmetic improved / did not change* $^{*}$ & 2 & 16 \\
Arithmetic worsened $^{*}$ & 7 & 7 \\
\hline
\end{tabular}

*Fisher, $p=0.020$; SPT: school performance test.

Table 5. Initial and final IQ means for the subgroups with (EA reduction) or without epileptiform activity reduction of $50 \%$ or more (EA no reduction) in the final evaluation and $p$ values in the comparisons.

\begin{tabular}{|c|c|c|c|c|c|c|}
\hline \multirow[b]{2}{*}{ IQ } & \multicolumn{2}{|c|}{ Initial } & \multirow[b]{2}{*}{$P$ value } & \multicolumn{2}{|c|}{ Final } & \multirow[b]{2}{*}{$P$ value } \\
\hline & $\begin{array}{l}\text { EA reduction } \\
\qquad \mathrm{N}=15\end{array}$ & $\begin{array}{l}\text { EA no reduction } \\
\qquad \mathrm{N}=17\end{array}$ & & $\begin{array}{l}\text { EA reduction } \\
\qquad \mathrm{N}=15\end{array}$ & $\begin{array}{l}\text { EA no reduction } \\
\qquad \mathrm{N}=17\end{array}$ & \\
\hline Verbal & 107.60 & 101.71 & $0.33^{*}$ & 104.27 & 102.18 & $0.88^{*}$ \\
\hline Performance & 105.53 & 98.12 & $0.39 *$ & 111.20 & 104.41 & $0.19^{*}$ \\
\hline Total & 107.00 & 99.88 & $0.33^{*}$ & 108.53 & 103.41 & $0.50^{*}$ \\
\hline Perceptual organization & 105.20 & 98.12 & $0.28^{*}$ & 111.13 & 105.59 & $0.26^{*}$ \\
\hline
\end{tabular}

*Mann-Whitney U test: $p>0.05$; EA: epileptiform activity.

Table 3 shows the distribution of the cases according to the performance in the SPT in the initial and final evaluations., On determining the corrected classification per school grade, their performance remained in the lower group in $50 \%$ or more of the children for writing, arithmetic and the total score. Although some children with inferior performance in reading or writing in the initial evaluations were classified as middle/upper in 
the final evaluation, the differences in the evolutive distribution did not reach statistical significance (Chi-square, $\mathrm{p}>0.05$ ). There were no significant correlations between the improvement in SPT and the evolution of the performance and perceptual organization IQ values.

A worsening in performance was observed in arithmetic for 14 (43.7\%) of the children (Chi-square, $\mathrm{p}=0.024)$.

\section{Relationship between the clinical,} electroencephalographic and cognitive aspects

No relationship was found between the WISC-III and the gender or age of the children.

No statistically significant correlation was observed between the occurrence of epileptic seizures during the period of accompaniment and any change in evolutive performance in the WISC-III (Chi-square, p>0.05).

A statistically significant relationship was found between the occurrence of epileptic seizures during the period of accompaniment and a worsening performance in the sub-test for arithmetic in the SPT in the final evaluation, when compared to the initial one (Fisher test, $\mathrm{p}=0.020$ ) (Table 4). On the other hand, such a correlation was not found for the total SPT for reading and writing.

The worsening performance in arithmetic in the SPT was not related to the use of anti-epileptic drugs (ChiSquare, $\mathrm{p}=0.96$ ).

No significant relationship was found between the age when the first seizure occurred and the evolutive performance in the WISC-III (improvement or stabilizing) or the SPT (Chi-square or Fisher's exact test).

There was no significant correlation between EA number and WISC-III and SPT results (Spearman correlation coefficients and Mann-Whitney test, respectively) in the initial and final evaluations.

There were also no statistically significant differences between the reduction in EA on the EEG (50\% or more) and performance in the SPT (Fisher's exact test or Chi-square test) and the WISC-III (Mann-Whitney U test, $\mathrm{p}<0.05$ ).

Table 5 shows the initial and final IQ means for the subgroups with or without epileptiform activity reduction of $50 \%$ or more in the final evaluation and $\mathrm{p}$ values in the comparisons.

\section{DISCUSSION}

The children evaluated in this study were accompanied for a mean period of 27.6 months and showed clinical, electroencephalographic and cognitive characteristics typical of BECTS 6

In the period of accompaniment, $28.12 \%$ of the children continued to have seizures and a significant reduction in the number of EA was observed on the final EEG and their complete disappearance in $6(18.75 \%)$ cases. Although an evolution in the clinical-EEG occurred, the majority of the children were still in the active phase of the "epileptic process" either according to the continuation of the seizures or of the EA.

In agreement with the literature, in this study the children with BECTS showed IQ values (WISC-III) within the limits of normality ${ }^{5,7,10-12}$, but still showed significant improvements in the performance and perceptual organization IQ values. This evolution was not related to characteristics of the locality or the side and number of EA. In a 2-year evolutive study, Baglietto et al. ${ }^{5}$ showed improvements in the performances in the total, verbal and performance IQ values, as related to the disappearance of EA on the EEG.

In this research, using an instrument that evaluates basic abilities for school performance, progress in the performance of the net scores was shown, but when corrected for school grade, the performance for arithmetic and writing remained in the lower group, in the inferior quartile, when compared to normal, healthy children in according with other studies ${ }^{17,18}$.

Some of the children moved from lower performance to middle/higher performance, but without statistical significance with respect to this evolution. A tendency for favorable evolution with respect to school performance could not therefore be considered ${ }^{10,11}$.

On the other hand various children remained in the inferior range for reading and writing performance in the SPT, concordant with a transitory stagnation phase or even regression in cognitive abilities such as reading and writing, as referred to by parents and teachers of children with BECTS ${ }^{2-5,8,19}$.

During the period of accompaniment a worsening in performance in arithmetic was observed, associated with persistence of the epileptic seizures, a relationship not found in the literature. The relationship between worsening performance in arithmetic with worsening in reading and writing referred to by Piccinelli et al. ${ }^{20}$ was not confirmed in the present study.

Other sporadic factors reported in the development of the cognitive changes such as an early start ${ }^{20}$, occurrence of numerous seizures, prolonged duration of the active epileptic phase $\mathrm{g}^{9}$ and the disappearance of the epileptic seizures ${ }^{4-6,11,21}$ were not confirmed in the present study.

Also, significant correlations were not found between characteristics of the EA, such as number, side or localization and cognitive evolutive aspects. However, in this study the presence of an intermittent slow-wave focus during wakefulness and the analysis of the first hour of sleep EEG recording were not assessed, and these EEG aspects could possibly correlate with educational impairments ${ }^{22}$. One of the mechanisms by which the EA of the EEG could interfere with cognition is that of the occurrence of transitory cognitive disturbances during the $\mathrm{EA}^{23}$. How- 
ever in a specific study about transitory cognitive disturbance in 34 children with BECTS, a transitory deficit was only observed in a small percentage of the children, suggesting that the EA is not necessarily a generator of cognitive or behavioral disturbances in the majority of cases ${ }^{24}$.

On the other hand EA indicates variable, cortical hyper-excitability at the time and location, and is, in general, ample and not exclusively focal, and could interfere in a chronic way in brain functioning, and, as a consequence generate neuropsychological difficulties ${ }^{2,3,25,26}$. A direct relationship between EA and cognitive disturbances has been difficult to document.

Some studies have suggested that children presenting an elevated number of EA on the EEG have lower IQ values ${ }^{19,27}$ or language disturbances ${ }^{11}$ and their cognitive performance tends to improve with normalization of the EEG.

There is controversy about the role of modifications in the functional representation of language occurring due to EA in the genesis of cognitive dysfunctions in some children in the active epileptic phase ${ }^{2,10}$. Different brain language organization may persist even after complete remission of the BECTS ${ }^{12}$.

According to the hypothesis of Doose et al.$^{28}$, another possible factor in the genesis of both the epileptic phenomena (seizures and EA) and cognitive and behavioral manifestations, could be a concomitant brain immaturity.

In conclusion, in the typical BECTS casuistry, evolving with a reduction in epileptic seizures and EA, there were improvements in performance with respect to IQ, but regression in arithmetic, the latter being related to recurrent continuation of the seizures.

A more prolonged study is required up to complete remission of the seizures and disappearance of the EA on the EEG for a better understanding of the neuropsychophysiological processes involved in this epileptic syndrome.

Other markers in the relationships with the cognitive aspects should be investigated, such as the characteristics of the basal cerebral electric activity, which are altered in BECTS ${ }^{29,30}$.

\section{REFERENCES}

1. Heijbel J, Blom S, Berfors P. Benign epilepsy of children with centro-temporal EEG foci. A study of incidence rate in outpatient care. Epilepsia 1975;16: 657-664.

2. Piccirilli $M, D^{\prime}$ Alessandro $P$, Tiacci $C$, Ferroni $A$. Language lateralization in children with benign partial epilepsy. Epilepsia 1988;29:19-25.

3. Staden U, Isaaca E, Boyd SG, Brandl U, Neville BGR. Language dysfunction in children with rolandic epilepsy. Neuropediatrics 1998;29:242-248.

4. D'Alessandro P, Piccirilli M, Tiacci C. Neuropsychological features of benign partial epilepsy in children. It J Neurol Sci 1990;11:265-269.

5. Baglietto MG, Battaglia FM, Tortonelli S, et al. Neuropsychological disorders related to interictal epileptic discharges during sleep in benign epilepsy of childhood with centrotemporal or rolandic spikes. Dev Med Child Neurol 2001; 43:407-412.

6. Massa R, Saint-Martin A, Carcangiu R, et al. EEG criteria predictive of complicated evolution in idiopathic rolandic epilepsy. Neurology 2001;57:1071-1079.

7. Papavasiliou A, Mattheou D, Bazigou H, Kotsalis C, Paraskevoulakos E. Written language skills in children with benign childhood epilepsy with centrotemporal spikes. Epilepsy Behav 2005;6:50-58.

8. Vinayan KP, Biji V, Thomas SV. Educational problems with underlying neuropsychological impairment are common in children with benign epilepsy of childhood with centrotemporal spikes. Seizure 2005;14:207-212.

9. D'Alessandro P, Piccirilli M, Sciarma T, Tiacci C. Cognition in benign childhood epilepsy; a longitudinal study. Epilepsia 1995;36(Suppl):S124.

10. Lindgren A, Kihlgren M, Melin L, Croona C, Lundberg S, Eeg-Olofsson O. Development of cognitive functions in children with rolandic epilepsy. Epilepsy Behav 2004;5:903-910.

11. Deonna T, Zesiger P, Davidoff V, Maeder M, Mayor C, Roulet E. Benign partial epilepsy of childhood: a longitudinal neuropsychological and EEG study of cognitive function. Dev Med Child Neurol 2000;42:595-603.

12. Hommet C, Billard C, Motte J, et al. Cognitive function in adolescents and young adults in complete remission from benign childhood epilepsy with centrotemporal spikes. Epileptic Disord 2001;3:207-216.

13. Engel J. A proposed diagnostic scheme for people with epileptic seizures and with epilepsy: report of the ILAE task force on classification and terminology. Epilepsia 2001;42:1-6.

14. Dalla Bernadina P, Chiamenti C, Capovilla G, Colamaria V. Benign partial epilepsies in childhood. In: Epileptic syndromes in infancy, childhood and adolescence. Ed John Libbey and Co. London \& Paris; 1985:137-149.

15. Stein LM. Teste de desempenho escolar: manual para aplicação e interpretação. São Paulo: Casa do Psicólogo Livraria e Editora Ltda., 1994.

16. Jasper $\mathrm{HH}$. The ten-twenty electrode system of the International Federation. Electroencephalogr Clin Neurophysiol 1958;10:371-375.

17. Miziara CSMG. Avaliação das funções cognitivas na epilepsia focal benigna da infância com descargas centrotemporais. Tese Doutorado. Universidade de São Paulo, São Paulo. 2003

18. Fonseca LC, Tedrus GMA, Tonelloto JM, Antunes TA, Chiodi MG. Desempenho escolar em crianças com epilepsia benigna da infância com pontas centrotemporais. Arq Neuropsiquiatr 2004;62:459-462.

19. Weglage J, Demsky A, Pietsch M, Kurlemann G. Neuropsychological, intellectual and behavioral findings in patients with centrotemporal spikes with or without seizures. Dev Med Child Neurol 1997;39:646-651.

20. Piccinelli $P$, Borgatti $R$, Aldini $A$, et al. Academic performance in children with rolandic epilepsy. Dev Med Child Neurol 2008;50:353-356.

21. Fonseca LC, Tedrus GMAS, Pacheco EMC, Costa D, Campregher AA, Berretta M.F. Benign chilldhood epilepsy with centrotemporal spikes: correlation between clinical, cognitive and EEG aspects. Arq Neuropsiquiatr 2007:65:569-575.

22. Nicolai J, van der Linden I, Arends JB, van Mil SG, Weber JW, Vles JS, Aldenkamp AP. EEG characteristics relates to educational impairments in children with benign chilldhood epilepsy with centrotemporal spikes. Epilepsia 2007;48:2093-2100.

23. Binnie CD. Cognitive performance, suble seizures, and the EEG. Epilepsia 2001;42(Suppl 1):16-18.

24. Fonseca LC, Tedrus GMAS, Pacheco EMC. Epileptiform EEG discharges in benign childhood epilepsy with centrotemporal spikes: reactivity and transitory cognitive impairment. Epilepsy Behav 2007;1:65-70.

25. Wolff M, Weiskopf N, Serra E, et al. Benign partial epilepsy in childhood: Selective cognitive deficits are related to the location of focal spikes determined by combined EEG/MEG. Epilepsia 2005:46:1661-1666.

26. Holmes GL, Lenck-Santini P. Role of interictal epileptiform abnormalities in cognitive impairment. Epilepsy Behav 2006;8:504-515.

27. Metz-Lutz MN, Kleitz C, De Saint-Martin A, Massa R, Hirosch E, Marescaux C. Cognitive development in benign focal epilepsies of childhood. Dev Neurosci 1999;21:182-190.

28. Doose H, Neubauer B, Carlsson G. Children with benign focal sharp waves in the EEG: development disorders and epilepsy. Neuropediatrics 1996:27:227-241.

29. Braga NIO, Manzano GM, Nóbrega JAM. Quantitative analysis of EEG background activity in patients with rolandic spikes. Clin Neurophysiol 2000;111:1643-1645.

30. Fonseca LC, Tedrus GMAS, Cerqueira J, Chiodi MG. Eletrencefalograma quantitativo em crianças com epilepsia benigna da infância com pontas centrotemporais: análise de freqüências. Arq Neuropsiquiatr 2004; 62:455-458. 